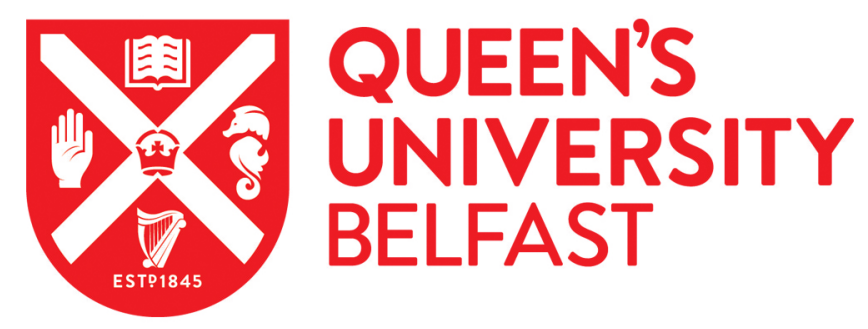

\title{
Strengthening stakeholder buy-in and engagement for successful exploration and installation: a case study of the development of an area-wide, evidence-based prevention and early intervention strategy
}

Hickey, G., McGilloway, S., O'Brien, M., Leckey, Y., Devlin, M., \& Donnelly, M. (2018). Strengthening

stakeholder buy-in and engagement for successful exploration and installation: a case study of the development of an area-wide, evidence-based prevention and early intervention strategy. Children and Youth Services Review, 91, 185-195. https://doi.org/10.1016/j.childyouth.2018.06.008

Published in:

Children and Youth Services Review

Document Version:

Peer reviewed version

Queen's University Belfast - Research Portal:

Link to publication record in Queen's University Belfast Research Portal

\section{Publisher rights}

Copyright 2018 Elsevier.

This manuscript is distributed under a Creative Commons Attribution-NonCommercial-NoDerivs License

(https://creativecommons.org/licenses/by-nc-nd/4.0/), which permits distribution and reproduction for non-commercial purposes, provided the author and source are cited.

\section{General rights}

Copyright for the publications made accessible via the Queen's University Belfast Research Portal is retained by the author(s) and / or other copyright owners and it is a condition of accessing these publications that users recognise and abide by the legal requirements associated with these rights.

\section{Take down policy}

The Research Portal is Queen's institutional repository that provides access to Queen's research output. Every effort has been made to ensure that content in the Research Portal does not infringe any person's rights, or applicable UK laws. If you discover content in the

Research Portal that you believe breaches copyright or violates any law, please contact openaccess@qub.ac.uk. 


\section{Strengthening stakeholder buy-in and engagement for successful exploration and installation: A case study of the development of an area-wide, evidence-based prevention and early intervention strategy}

\section{Accepted for publication: Children and Youth Services Review 10.1016/j.childyouth.2018.06.008}

Grainne Hickey $^{1 \dagger}$, Sinead McGilloway ${ }^{1}$, Morgan O’Brien ${ }^{2}$, Yvonne Leckey ${ }^{1}$, Maurice Devlin $^{3} \&$ Michael Donnelly

${ }^{1}$ Department of Psychology, National University of Ireland Maynooth

${ }^{2}$ Department of Humanities, Institute of Technology Carlow.

${ }^{3}$ Department of Applied Social Studies, National University of Ireland Maynooth

${ }^{4}$ School of Medicine, Dentistry and Biomedical Sciences, Queen's University Belfast

$\uparrow$ Corresponding author: grainne.hickey@mu.ie

Address: Maynooth University Department of Psychology, John Hume Building, North Campus, National University of Ireland Maynooth, Co. Kildare, Ireland 


\begin{abstract}
Background: The implementation of evidence-based programmes (EBPs) designed to improve outcomes for children and young people and prevent disadvantage is an increasingly important international policy imperative. However, the integration of EBPs into existing service settings and systems is a complex and multifaceted undertaking.
\end{abstract}

Methods: A process evaluation was conducted to appraise the design and development of a large-scale, area-based, prevention and early intervention initiative. This initiative, called Youngballymun, consisted of five service strategies comprising a range of EBPs (e.g. the Incredible Years Programme, Highscope) targeted at children and young people and their families (from birth to 20 years). The initiative was designed to promote the development, adoption and implementation of EBPs within routine children and youth services in a disadvantaged urban area in the Republic of Ireland. The analytical approach involved the systematic analysis and triangulation of data obtained from relevant documentation (e.g. programme manuals, meeting minutes), as well as a series of one-to-one interviews ( $\mathrm{n}=27)$ and six group discussions with key stakeholders $(\mathrm{n}=29)$.

Results: Adopting aspects of an implementation stages framework (Fixsen et al., 2005), we examined the key implementation stages of exploration and installation. Data gathering and needs assessment and strategic organisational development played an important role in implementation. However, resistance to innovation amongst local service providers emerged as a major challenge to implementation. Factors identified as crucial to overcoming this challenge and promoting stakeholder buy-in for innovation included: encouraging and supporting stakeholder engagement; and adopting a flexible approach to implementation planning.

Conclusion: Generating buy-in amongst stakeholders is central to ensuring a fit between innovative programmes and practices and the systems in which they are to be embedded. Some key lessons, such as the need for the active involvement of community-based service providers in the planning process at the earliest stages of implementation, are identified. The kinds of implementation strategies that may be used to address challenges to practice change and innovation, particularly stakeholder responsiveness to, and perceived compatibility of, EBPs, are discussed.

Key words: Implementation; Implementation stages; Intervention appropriateness; implementation strategies; stakeholder buy-in; evidence-based programmes 


\section{Introduction}

Early exposure to social adversity is linked to poorer outcomes across the lifespan, including behavioural and socioemotional maladjustment, educational under-attainment, poor health outcomes and dependence on the welfare system (Metzler, Merrick, Klevens, Ports \& Ford, 2017; Repetti, Taylor \& Seaman, 2002). These outcomes may often occur from one generation to the next, perpetuating a cycle of disadvantage and inequality in the same families (Serbin \& Kemp, 2004). However, it is now recognised that comprehensive early intervention and prevention programmes can successfully address these kinds of maladaptive trajectories (Anderson et al., 2003).

Many countries have developed, or are in the process of developing, policies designed to promote positive child outcomes as a means of preventing and reducing intergenerational disadvantage (Black et al., 2016; Britto et al., 2016). An increasingly popular policy and approach that aims to tackle childhood inequality, involves the delivery of area-based prevention and early intervention services. These strategies target resources at a defined geographical area to tackle disadvantage and involve representatives, advocates and groups from across the community in planning and implementing services and innovations (Sridharan et al., 2007).

Area-based strategies often comprise evidence-based programmes (EBPs) that have been proven to help to improve outcomes for children and young people (Novins, Green, Leghan \& Aarons, 2013; Shapiro, Prinz \& Sanders, 2011). The use of EBPs can lead to significant economic benefits due to their ability to prevent and/or ameliorate the need for costly intervention later in life (Heckman, 2011). Increasingly, the use of EBPs in health and social care services is becoming mandated (Reding, Chorpita \& Innes-Gorberg, 2013), a trend which is also reflected in the increasing drive toward evidence-based service delivery in child and youth services (Allen, 2011). However, there are significant barriers to embedding effective practices and programmes in child and youth services (Proctor, Powell \& McMillen, 2013; Powell et al., 2015), with the result that the uptake and implementation of EBPs across family services is often inconsistent and limited (Novins et al., 2013). Therefore, it is crucial to explore how EBPs are adopted and installed within usual care systems and services for children and young people and the factors that influence this process (Berlin, Brooks-Gunn \& Aber, 2001; Horwitz, Chamberlain, Landsverk \& Mullican, 2010).

\subsection{Implementation and intervention-context fit}

Implementation is recognised as a complex, multiphasic process which involves many varied resources, inputs and activities (Hasson, 2010; Fixsen, Blase, Metz \& Van Dyke, 2013). The implementation stages framework (one of the five frameworks which forms part of the Active Implementation Framework; Fixsen et al., 2005), recognises implementation as a dynamic process. Within this well-established and widely used framework four functional stages of implementation are identified: exploration, installation, initial implementation and full implementation (Metz et al., 2015). Exploration and installation can set the stage for initial implementation and, over the longer run, influence the success and sustainability of new programmes and practices (Odom et al., 2013; Panzano \& Roth, 2006). During exploration, a community or service need must be recognised, a potential programme or practice which may address that need must be identified and the assets or resources required to support implementation must be assessed (Metz, 2013). The installation stage refers to the activities 
needed to prepare for programme implementation and involves acquiring and/or developing the resources and supports which are important for implementing innovative practices (Fixsen et al., 2005).

The factors which influence and shape the implementation process as it unfolds, are varied and wide ranging (Hurlburt et al., 2014; Nilsen, 2015). Indeed, it is increasingly recognised that for implementation efforts to be effective, fit between those innovations and the systems in which they are implemented is vital (Aarons \& Sommerfeld, 2012; Berkel, Mauricio, Schoenfelder \& Sandler, 2011). Many implementation theories, models and frameworks (e.g. Diffusion of Innovation; Consolidated Framework for Implementation Research) have highlighted the importance of intervention-setting fit (Damschroder et al., 2009; Rogers, 2010; Tornatsky \& Klein, 1982). Proctor and colleagues (2011) use the term "appropriateness" to refer to the perceived compatibility between an innovation and the implementation setting. Perceived fit between implementation settings and EBPs is particularly pertinent to the early stages of the implementation process and may exert an influence on the adoption of effective programmes (Lyon et al., 2014). The responsiveness and meaningful engagement of practitioners and implementers or their buy-in for an evidence-based program or practice, is an important feature in environments conducive to implementation (Greenhalgh, Robert, MacFarlane, Bate \& Kyriakidon, 2004). An absence of buy-in for EBPs is likely to stymie innovation before it can be adopted or compromise its effectiveness if implemented. Conversely, engagement and commitment amongst key stakeholders can nurture and sustain innovation (Cabassa \& Baumann, 2013).

Although research on implementation has developed considerably in recent years, there remains much to learn about how to successfully align the implementation of EBPs with existing child and youth service resources and capacities. The issue of fit between EBPs and the setting they are implemented remains under-researched and further exploration of strategies which can successfully address the compatibility between a given intervention and the implementation context is needed (Lyon et al., 2014). Implementation strategies comprise "the specific means or methods for adopting and sustaining interventions" (Proctor et al., 2013; 139). A wide array of implementation strategies which can be used in community and/or professional practice settings to enhance implementation efforts have been identified (Powell et al., 2015).

Powell and colleagues (2015) developed a detailed and comprehensive compilation comprising 73 implementation strategy terms and related definitions. Several strategies identified therein are relevant to the potential interaction between implementation efforts and the context in which implementation occurs, whilst they may also be pertinent to addressing intervention-setting 'compatibility'. Strategies such as those aimed at 'assessing readiness and identifying barriers and facilitators' or conducting a 'local needs assessment' within communities may help to build an understanding of key stakeholders' perceptions of a proposed intervention and its appropriateness to the context. Local consensus discussions are an implementation strategy which Powell and colleagues define as involving local providers/stakeholders in discussions to explore the appropriateness of a planned intervention and identify stakeholder priorities and may also be a potentially effective implementation strategy for helping to address intervention-setting fit. These strategies may be used in a stand-alone manner or as part of a larger multifaceted implementation plan. Nevertheless, the 
manner in which strategies such as these might be used to address intervention-setting fit, successfully promote positive stakeholder perceptions of innovation and secure buy-in for programme adoption and practice change remains under-researched. Indeed, Powell and colleagues (2015) note that further research is needed to determine the evidence-base and causal mechanisms inherent in these kinds of implementation strategies, as well as their utility in different circumstances.

\subsection{The current study}

In this paper we present the findings of a detailed case study of the design and early implementation of an area-based prevention and early intervention initiative called Youngballymun (youngballymun.org). This initiative aimed to embed EBPs, on an area-wide basis, within usual care services for disadvantaged children and young people living in an area of Dublin, called Ballymun. This case study formed part of a larger theory-based evaluation of the Youngballymun initiative which was undertaken to appraise and understand its aims, inputs, outputs, activities, processes and outcomes, to examine barriers/facilitators to successful implementation and to identify the causal processes and mechanisms that are anticipated to lead to intended or expected outcomes (Reference withheld for anonymous review). The evaluation was conducted by an independent research team who had no involvement in the set-up, delivery or implementation of Youngballymun.

The aims of this case study were: (1) to analyse the planning processes involved in the exploration and installation phase of the Youngballymun initiative; and (2) explore the facilitating and inhibitive factors which influenced the uptake of EBPs within child and youth services, with a particular focus on the implementation strategies used across the early implementation of the Youngballymun initiative and their efficacy in securing buy-in for innovation and in addressing intervention appropriateness.

\subsubsection{Study context and background}

Ballymun is a suburban area of North Dublin in the Republic of Ireland, with a population of approximately 16,500. It is one of the most economically disadvantaged neighbourhoods in Ireland and has a complex history. The area originally comprised seven 15-storey flat blocks, 19 eight-storey blocks, 10 blocks of four-storey flats and 2400 houses which were constructed between 1965 and 1969 (Somerville-Woodward, 2002). A number of factors, particularly, a lack of amenities, poor services and insufficient maintenance of the social housing development by the local authority, contributed to deteriorating living conditions in the area. Later, during the 1980s, high tenancy turnover deepened existing socioeconomic disadvantage and social problems (Boyle, 2005). Community activism emerged in response to these issues and an unprecedented, large-scale and ongoing regeneration plan for Ballymun was established in 1997 (Government of Ireland, 2007). This regeneration led to considerable transformation of the physical environment, but social and economic development still lagged behind the national average (Kintrea \& Muir, 2009). Outcomes for children and young people in the disadvantaged community of Ballymun, have been found to compare unfavourably to national averages including: low literacy levels and educational performance/attainment; poor levels of transfer to, and completion of, second level education; and a high prevalence of conduct disordered and attention-deficit hyperactive-type behaviours (Ryan, 2004).

The Youngballymun initiative was established in 2007 as one of three new prevention and early intervention programmes, jointly funded by the Irish Government's Department of 
Children and Youth Affairs (DCYA) and The Atlantic Philanthropies, formerly an American philanthropic organisation aimed at tackling and reducing disadvantage and inequality in a number of countries throughout the world including the Republic of Ireland (DCYA, 2008). The initiative was aimed at promoting and implementing evidence-informed programmes within existing services for children and young people and their families. As such, the initiative was not established to deliver programmes per se, but rather to support the implementation, mainstreaming and embedding of EBPs in both statutory (health care and education services) and non-statutory (community/voluntary services) services operating within the locality including: antenatal and public health nursing services, primary and secondary schools in the area, crèches/early childcare centres, social work, family resource centres and youth work services.

Overall, Youngballymun comprised five overarching service strategies (see Table 1): (i) "Ready, Steady, Grow", aimed at supporting pregnant women and their infants aged 0-18 months through the implementation of the Parent-Child Psychological Support Programme (the Irish version of the Programa de Apoyo Psicológico P/Materno-Infantil (Cerezo, Dasi \& Ruiz, 2013); (ii) "3,4,5 Learning Years" which was aimed at supporting the implementation of the HighScope programme (Epstein 2007; Hohmann \& Weikart, 1995) and enhancing the quality of early years child care and education services (targeted at preschool children aged 0$4 / 5$ years), as well as supporting the implementation of Síolta (the national quality framework for early childhood education); (iii) the Incredible Years (IY; Webster-Stratton \& Reid, 2003) including the implementation and delivery of the IY Parent, Teacher and Child training programmes; (iv) "Write Minded", a literacy strategy integrated into primary and secondary educational institutions in the Ballymun area (children aged 4-18 years); and (iv) "Jigsaw" a youth mental health service for young people aged 12 to 18 years. Thus, the Youngballymun strategy comprised, in some instances, well-established and well-known evidence-based programmes (e.g. the Incredible Years programmes, HighScope), whilst in others the aim was to establish evidence-based practices within child and family service settings in the area. For example, the Write-Minded literacy strategy was developed to promote and support the use of evidence-informed approaches to literacy instruction by teachers within classrooms and across the whole-school setting such as those recommended by the Chicago Reading Framework (Tierney \& Shanahan, 1991) (e.g. word knowledge, reading, fluency, reading comprehension and writing). Likewise, Jigsaw was aimed at supporting the development of wraparound intervention practices within youth services, an evidence-based approach to youth service provision (Burns, Schoenwald, Burchard, Faw \& Santos, 2000).

\section{[Table 1 about here]}

\section{Method}

\subsection{Study design}

Evaluating a large-scale, community-based initiative such as Youngballymun, is a complex undertaking. The complexity, size and scope of these kinds of community change / areabased initiatives require a strong focus on processes of change and on documenting and analysing the "how and why" of the programme (Saunders, Evans \& Joshi, 2005). Process or theory-based evaluations, typically focus on collecting qualitative data and aim to provide a rich description of implementation activities and the mechanisms which underpin a programme or initiative (Lafferty \& Mahoney, 2003; Moore et al., 2015). 
When this research was commissioned, Youngballymun was in initial stages of implementation; thus, a retrospective case study of the design and development of the initiative was conducted as a preliminary phase of the larger theory-based evaluation. We examined the exploration and installation stages of the Youngballymun initiative using aspects of the implementation stages framework (Fixsen et al., 2005), with a view to identifying the implementation strategies and contextual factors that influenced the establishment of the initiative. The focus of this case study, is not to evaluate the uptake of the specific, individual evidence-based programmes outlined above and their delivery to children and families in the Ballymun community; but rather to examine, from a broader perspective, the process and factors which influenced the development and installation of an evidence-based, area-wide prevention and early intervention initiative.

\subsection{Data sources}

Multimethod approaches which draw on a range of qualitative data sources are common in theory-based evaluation research and can enhance the quality and utility of the data and analysis generated (Bledsoe \& Graham, 2005; Moore et al., 2013). Youngballymun comprises a complex programme of programmes and practices, whilst a range of different actors, organisations and conditions were also pertinent to its implementation. Thus, a pluralistic approach to data collection was adopted to enable flexible and in-depth insights into implementation processes and how they played out under differing conditions and settings. Three key data sources were used in the current study including: (i) key documentation; (ii) 27 one-to-one interviews; and (iii) six focus groups $(\mathrm{n}=29)$. The document analysis involved the review and critical analysis of a wide range of relevant documentation including: the original service proposal; the Youngballymun implementation plan and logic models; meeting minutes, reports \& proposals; official Youngballymun documents, reports and policy and research papers; policy documents and demographic data; and online promotional and informational materials. As this research was retrospective in nature, the document analysis was instrumental in developing a detailed understanding of the timeline of programme development and evolution, as well as identifying areas for further exploration and refining ideas and analyses. An overview of the methodological approach is provided in Table 2.

\section{[Table 2 about here]}

\subsection{Participants and data collection}

A process of purposive sampling was used whereby participants were purposefully recruited to the study because of their involvement in the design, development and/or initial implementation of the Youngballymun initiative and/or delivering services to the Ballymun community. Interview participants included: (i) key stakeholders involved in planning the design and development of the Youngballymun initiative $(n=5)$, policy makers and funders $(\mathrm{n}=3)$; (ii) key stakeholders involved in the governance (e.g. board members) and implementation of Youngballymun (e.g. staff members) $(n=6)$; (iii) and local service providers involved in the on-the-ground delivery of the Youngballymun service strategies $(n=13)$.

Group discussions were conducted to bring larger numbers of participants into the data collection process and additional members of the Youngballymun staff team and local service providers. Thus, staff members from across all of the five Youngballymun service 
strategies were included in the data collection processes, whilst local service providers were sampled from statutory and community/voluntary sectors, including: health care professionals (e.g. public health nurses, psychologists), social care workers (e.g. family support workers, youth workers, social workers, managers of community resource services) and educators (e.g. school principals, teachers, early childcare professionals). At the time of data collection, all of the participants were involved in delivering services to the Ballymun community and/or in developing or implementing the Youngballymun initiative and its suite of services. The individual characteristics of these participants (e.g. age, years of experience) was not collected; nevertheless, many of the participants had worked in the Ballymun community for a significant number of years, whilst others were taking up new role in a Youngballymun initiative and were relatively new to the Ballymun service community.

\subsection{Data analysis}

All data were analysed using thematic analysis (Braun \& Clarke, 2006). The analytical technique involved four key stages: familiarisation, coding, defining themes and interpretation. This process was supported by the use of MaxQDA, a qualitative data analysis software package. The familiarisation stage involved an in-depth reading of all the data and generating detailed summaries. Summaries included paraphrasing quotes from interview and group discussion transcripts and recapping and reviewing documents. This was followed by identifying initial codes to explain the data. These codes were developed by interrogating the data and linking narrative content to larger, more general processes or categories which capture the meaning of the data. This led to specification of attitudes, relationships, activities and events which were inherent in the data. Later stages of analysis involved the integration of codes into an overarching thematic framework which charts links and associations, as well as discrepancies and differences within the data.

The final stage of analysis involved finalising conclusions and interpretations. This involved determining the strength and depth of the findings or themes. For example, we assessed the prevalence of attitudes or the nature and range of processes and activities. Blending findings from across differing data sources was important in this stage of the analysis. This process of data triangulation was adopted to gain a full perspective on our findings and conclusions. Triangulation consisted of integrating narrative accounts with findings from the document analysis, as well as comparing different accounts and different data sources. Findings which emerged across different data sources were considered strong in nature. Other themes and conclusions which were weakly supported were collapsed into other categories or, where appropriate, discarded.

The 'position' of participants, or the participants' expertise, group membership and relationship to Youngballymun were also critical considerations during the analytical process. The focus of this qualitative analysis was on illuminating meanings, perceptions and experiences of particular groups or persons; thus, the data cannot be considered to represent truly 'objective' or independent accounts. Documents, likewise, cannot be considered an independent or objective account of a phenomenon, process or event; rather, they represent particular values and ideas. This type of reflexivity was important factor in determining the strength of the findings. For example, the overarching participant sample was made up of different sub-groups with differing levels of involvement in the Youngballymun initiative. A relatively small sub-group of participants $(n=5)$ were involved in the initial planning stage 
of the Youngballymun initiative; however, because of their key role in shaping the early planning stages, recurring themes expressed by these participants were considered a strong finding due to their central and significant involvement in the planning process.

\subsection{Ethical considerations and data management}

All participants were informed of the study both verbally (by a member of the research team) and in writing by means of an information sheet. Written informed consent was obtained from all interview and group discussion participants. All interviews and group discussions were audio recorded with consent and transcribed verbatim. After transcription audio recordings were destroyed, while transcripts were anonymised and stored separately from consent forms. References to names or potentially identifying information (e.g. the participant's work role or the name and/or type of service where the participant worked at the time of interview) were removed to ensure anonymity and confidentiality. Transcripts and documentary accounts were allocated identifiers to ensure the systematic analysis and anonymity of data sources; 'Dx' represents findings from the document analysis where ' $D$ ' denotes document and ' $x$ ' represents an allocated document number; one-to-one interviews and group discussions are respectively identified as ' $\mathrm{Ix}$ ' and ' $\mathrm{Gx}$ '.

\section{Results}

The results are presented in two main sections detailing: (1) the exploration stage of the Youngballymun initiative; and (2) its installation within the Ballymun service landscape. Key themes related to core activities and strategies used to propel implementation across these two planning stages are described.

\subsection{Exploration stage}

The Youngballymun initiative evolved from the groundwork of the Ballymun Development Group (BDG) which comprised nine key stakeholders including service executives and managers active in the Ballymun community, as well as an external chairperson. The group was formed when The Atlantic Philanthropies (AP) approached local stakeholders to instigate a planning process for a comprehensive, area-based prevention and early intervention programme in the area. This formed part of a wider policy-focused strategy aimed at promoting investment in evidence-based services for children and young people, called the Prevention and Early Intervention Programme (PEIP; DCYA, 2008).

\subsubsection{Needs analysis and data gathering}

Needs analysis and data gathering formed a core activity of the planning group during the exploration stage. An external planning advisory consultant was appointed to provide expert advice on the planning process only and helped the BDG to develop an eight point planning process/framework to inform the development of the Youngballymun initiative. This planning framework focused on gathering data from the local community, conducting needs analyses, auditing existing services, building an understanding of the relevant policy context, identifying evidence-based services and engaging with local stakeholders and decision makers (Box 1). In line with this planning framework, a range of research and community consultation exercises were undertaken to propel and inform the planning process and to identify key community issues and existing needs within Ballymun, particularly those faced by children and young people. Data gathering included: (i) 11 focus groups conducted with input from 103 local service providers drawn from a range of agencies across the Ballymun community (D11); (ii) two "community consultation days" held in the local shopping centre 
and elicited information from 528 local residents (D12); (iii) 10 focus groups with 69 children and young people (33 girls and 26 boys aged 3-20 years) recruited through local crèches, schools and educational centres in the Ballymun community; (iv) a survey of parents of children aged four years $(n=95)$ and children aged 11 years $(n=91)$ and 16 years $(n=85)$ (D13); (v) and a further survey of parents of children aged 4-17 years ( $\mathrm{n}=128)$ (D14). A separate literature/research review to identify evidence-based prevention and early intervention programmes, whilst an audit of existing services in Ballymun and a policy review was also conducted (D20). Overall, this data gathering and analysis procedure informed the development of the following vision statement which encapsulated the overarching aims and objectives of the initiative:

"In Ballymun, we want our children and young people to flourish and be happy; to live in nurturing families, to be healthy and emotionally strong, to be educated and equipped to reach their full potential, to be confident, motivated and aspirational citizens and to live in a stimulating physical environment, which is safe and secure." (D1)

\section{[Box 1 about here]}

Overall, the process of needs analysis and data gathering helped to identify community and child and family needs across a range of developmental domains, including: parenting difficulties; parent well-being; child behavioural difficulties; literacy challenges and learning difficulties amongst school going children; early school leaving; and high levels of family socioeconomic disadvantage (BDG, 2006). In addition, insufficient access to parenting and family services and supports, youth services and activities were highlighted, as well as a need for greater integration and collaboration across community-based services (Hayes \& Bradley, 2006; McKeown \& Haase, 2006). In turn, these findings helped to highlight several key action areas where the implementation of EBPs was needed, particularly around parenting and family services and supports, youth services and education. Subsequently, several EBPs were identified which were intended to meet identified needs in the community and which would be implemented across various child and youth services. Other important ingredients for a successful strategy were also highlighted, including the need for greater integration and collaboration within community-based services.

"We [were] very interested [in] doing a really proper identification of needs. And then, once those needs are identified - actually kind of looking to best practice, evidence informed practice, predominantly internationally in terms of programmes that could be applied to address the needs that have been identified." [I13, BDG member]

Overall this work was intended to help build a consensus around innovation and implementation. At this point in the planning process, a detailed service outline and logic model for the planned Youngballymun was developed by the BDG and submitted to the Department of Children and Youth Affairs and the AP for approval of funding. Although the proposal was successful, it was recognised by the BDG that data gathering and consultation events conducted up to this point in the planning process had not been sufficient to establish broad support for implementation amongst the wider service community and that more work 
would be needed to bring implementation partners into the process of service development and delivery.

“...not everybody, absolutely not everybody that would be thinking about children in this way that [planning] certainly wasn't successful in getting interagency cooperation [going] or even beginning to break that kind of barrier down” [I14, BDG member]

"I suppose what became clear at that point was, while there had been something of a process to actually develop the strategy and consultation with key members of the community to develop the strategy, that wasn't sufficient, that wasn't robust enough. And actually what we needed to do was to bring people into a much more participative service process." [I12, Youngballymun staff member]

"And there was a lot of scepticism, people saying we were not going to put any money in, it is all talk and what is going on here." [I3, BDG member / Youngballymun board member]

"It was raising expectations and as a community I would be getting it in the ear a bit, "what is going on here, when are these people going to do something?' " [I4, BDG member / Youngballymun board member]

\subsection{Installation stage}

The installation of Youngballymun aimed to "develop organisational identity and strategic planning capacity to drive systemic change within the Ballymun community" and involved "establishing Youngballymun structures for governance, planning, implementation \& engagement” (D37). The triangulated analysis identified several key themes related to important activities/strategies and conditions which impacted on the installation process including: strategic development; challenges to innovation adoption (particularly, resistance to implementation); and responding to challenges through promoting local engagement in the planning process and flexible planning processes.

\subsubsection{Strategic organisational development}

The installation of the Youngballymun initiative involved a process of strategic organisational development, namely the establishment of organisational structures and the acquisition of appropriate resources and facilities to support implementation. The funding awarded to the initiative ( $€ 16$ million) enabled the recruitment of a core staff team $(n=7)$ which were responsible for overseeing the implementation of the strategy. During subsequent months, a further 15 people were recruited to support the implementation of identified EBPs within the locally-based services, to provide training and coaching to implementers and to monitor implementation progress over time. These staff members were seconded from local services or recruited through national/external organisations and included individuals with good local knowledge or established relationships within the Ballymun community.

Overall, this process of organisational development was intended to put in place the "systems and structures [needed] to better achieve their objectives" (D27). In other words, organisational building was aimed at creating a platform for implementation and allowing the Youngballymun initiative to pursue its vision for innovation and EBP implementation. This 
approach was aimed at creating and establishing vital assets, which would, in turn, promote involvement in and uptake of EBPs within locally-based child and youth services and, more specifically, the incorporation of the Youngballymun service strategy (as outlined in Table 1) into the practices of community-based service providers.

\subsubsection{Resistance to implementation}

Challenges to implementation included resistance from local stakeholders and dissatisfaction with/lack of support for aspects of the proposed service/programme strategies Thus, before further capacity development for implementation could take place (e.g. training and coaching for service providers), significant barriers had emerged to the adoption and implementation of the proposed Youngballymun programme of work and innovation.

Some initial tensions emerged, early in the lifespan of the initiative, between the new organisation and the community-based services who were intended to implement the identified EBPs. Notably, some local service providers perceived an incongruence between features of the proposed strategy and existing community priorities, practices and resources, whilst issues of 'turf' and responsibility also began to emerge. Further difficulties arose between Youngballymun and several community-based groups which was indicative of a perceived lack of engagement and collaboration by Youngballymun with community-based service providers, as well as concerns that the new initiative would assume and/or duplicate the work and responsibilities of these organisations, and claim the credit for their work. Notably, Youngballymun was established during a period of deep economic recession and the perception was that the wider economic context of funding cuts for local services contributed to a sense of resentment and resistance amongst some local service providers. As one senior member of Youngballymun noted:

"The community ones (service providers) were saying like, "we're already doing this, and we're already running these programmes, so why didn't they come to us first..." there's loads of places around here that have gotten money taken off them, funds cut and stuff like that... like people were losing their jobs... that's what a lot of the jealousy was from; like 'why did they get 16 million?' " [I8, Youngballymun staff member]

Overall, the key challenges raised by local service providers at this point in the implementation processes, may be categorised into two key themes: (i) dissatisfaction with the manner in which the planning process had been conducted to date; and (ii) a perceived lack of compatibility between the proposed innovations and existing services and practices. In relation to the former, differences had emerged across sectors/services; for example, in community/voluntary sector services (including childcare centres and youth work services), the proposed innovations were perceived more positively. Indeed, in some cases, services had already been using the planned EBPs, albeit on a smaller, more limited scale. Conversely, in the public education sector (e.g. primary and secondary schools in the area), key stakeholders raised significant concerns regarding the viability of implementing the proposed literacy service. These concerns centred on the potential lack of local resources for implementation and a perceived mismatch with existing, and statutorily required, school services and programmes. 
Notably, the resistance which emerged at this point cannot be simply attributed to a lack of understanding/knowledge of evidence-based services and practices, or a fear of change. Rather, this was rooted in a lack of consensus and disagreement surrounding the feasibility of proposed services and the optimal programmes and practices for achieving better outcomes for service users. At this point in the planning process, strategic decisions regarding adoption and installation had been made by stakeholders operating in a top-level management capacity, whilst service providers operating at the local level had not been involved and, indeed, perceived themselves as having been excluded from the planning process. Thus, a perception emerged of the initiative as having been developed by means of a top down process and as introduced to the community as an established package without sufficient consultation (Box 2). Importantly, the proposed Youngballymun initiative comprised a large-scale programme for community change. The scale of the proposed programme of innovation is likely to have contributed to the emergence of these kinds of challenges during installation which targeted a broad range of different stakeholders and services from across different service sectors. Moreover, at the local service level and within the Ballymun community more generally, there is a long history of social activism and selfempowerment, as well as significant commitment to improving wellbeing in the community (Boyle, 2005).

\section{[Box 2 about here]}

\subsubsection{Responding to the challenges}

Two key aims of Youngballymun outlined in relevant documentation during this stage were to establish: "Positive attitudes towards the importance of evidence-informed prevention and early intervention"; and more broadly, "positive perceptions of Youngballymun services and approach by service providers" (D29). The findings from the analysis reveal two key factors which were important in overcoming challenges to innovation and promoting adoption and implementation including: (i) promoting engagement; and (iii) adopting a flexible approach to implementation planning. It is important to note, that this process of engagement and additional implementation planning required a greater investment of time in the planning process than was originally envisaged by the programme developers and resulted in a temporally lengthy planning process.

\subsubsection{Promoting engagement}

Five Implementation Teams (ITs) were put in place by the newly established Youngballymun initiative to facilitate the participation of community-based service providers in a new service design process. Participants across each of these ITs included Youngballymun staff members and local service providers from statutory (e.g. schools, primary health care services) and non-statutory services (crèches, family and youth resource centres) in order to "secure maximum community involvement in the work of Youngballymun" (D35). The teams, therefore, were focused on a bringing together a broad range of key local stakeholders involved in service provision and were intended to be an inclusive and collaborative platform for engagement. Importantly, these structures were seen as a vehicle for buy-in for implementation of the Youngballymun strategy:

"Multi-disciplinary teams of stakeholders whose role is to ensure that [Youngballymun] services are integrated into what already exists [and] ensuring ownership of, and ongoing 
engagement in, the common purpose of achieving improved outcomes for children and young people” (D35)

Findings from the interviews and group discussion, indicate that the response from local stakeholders to this new planning process was generally positive:

"That [implementation team] was an excellent process. [...] the energy that was been put in from all the different areas was quite significant. [...]. I would go away with a sense of, that's good work, well done, they are getting on with that." [I14, BDG member]"

“Huge learning for me. I found it very engaging and very, very interesting." [I2, local service provider - Community and voluntary sector]

"So we would have a long discussion about where we are going, what we want, what would it look like, [...] I would go away with a sense of, that's good work, well done” [G3, local service provider - Community and voluntary sector]

This process of engagement led to the development of a five-service, multi-faceted strategy (Table 1) designed be embedded within mainstream services delivered in the locality. Changes to the planned initiative which emerged from this phase of the planning process included mainly: (i) the redevelopment of aspects of the proposed EBPs/identification of alternative EBPs which were perceived as having better fit with the service environment; and (ii) the modification/enhancement of service elements in order to better meet the needs of key stakeholders. This led, in turn, to more positive perceptions amongst local stakeholders, around the content and feasibility of the Youngballymun strategy:

"When they got other community services on board [through] their Implementation Teams that it actually became up and running... There was a bit of a gap in the beginning... but in order to get the service up and running, they need to come through existing organizations." [I3, BDG member / Youngballymun Board member]

\subsubsection{Flexible approach to implementation planning}

The work of the ITs was underpinned by a flexible, formative approach to implementation planning. This flexibility was evident at two levels: (i) in the approach of programme developers/planners to the planning process itself and the adoption of a more open and inclusive approach to the development of the Youngballymun strategy; and (ii) in a willingness to revise and adjust adoption decisions, implementation protocols, plans and processes. Ultimately, this open and formative approach to programme exploration and installation helped to facilitate engagement and satisfaction with the service design process, as well as increasing buy-in and commitment for implementation.

"That was absolutely the right thing, to not try and hold on and say, 'no but we are doing this'. [...]... I think that there is huge value in the approach that they took. And that is right from the planning stage where the mistakes were made and it was rather then, well you have 
to keep going now or say nothing and pretend the mistake didn't happen. They were very supportive of, 'well let's get it right rather than do it wrong just because you have gone this far'”. [I12, Youngballymun staff member]

"We took a very definite view that the point of the exercise was not to 'bend' the community and the organisations [...] ... and it would not have the dynamics of having you know, "[...] I'm sitting here to tell you what to do" - that would not be right...” [I7, Youngballymun board member]

"I feel that we were very influential in actually designing the service. [...] It was really good, you just had to turn up and say, 'this is what I think should happen, this is how I think it should work.' And they were really facilitative in doing that, I thought. [Youngballymun] was very good in facilitating what did people think, what did people want" [G2, local service provider; Health sector]

In summary, the adoption of a relationship building, responsive approach to implementation planning was crucial to overcoming challenges to implementation. Overall, this process was successful in building commitment for implementation amongst decision makers and practitioners within individual services. More specifically this process helped to: build partnership for implementation and facilitate the involvement of organisations in the implementation process; remove barriers to engagement; help to diffuse resistance to change; and secure buy-in for strategy implementation.

\section{Discussion}

The findings highlight the crucial role of stakeholder priorities and responsiveness in influencing adoption decisions and implementation efforts. To date, there are only limited 'real world' case examples which explore the factors that influence the processes involved in the exploration and installation of EBPs in community-based children and youth service settings (Akin, Strolin-Goltzman \& Collins-Camargo, 2017). Our findings provide further evidence that a receptive environment for innovation - which is characterised by positive perceptions of the planned innovation, agreement on implementation between key stakeholders and positive collaborative relationships - must be in place to allow for the effective adoption and implementation of EBPs. This case study further illustrates that key challenges to the exploration and installation process of a comprehensive prevention and early intervention initiative, primarily centred on inadequate buy-in for innovation and service implementation. Importantly, considerable funding for the implementation of childand youth-focused EBPs had been secured, infrastructure and resources were put in place to support implementation, whilst backing for evidence-based service provision at a policy/government level was also apparent; nevertheless, implementation could only be successfully realised when buy-in for innovation was generated at a local level.

As outlined earlier, the perceived fit or 'appropriateness' of an intervention is crucial to the uptake of EBPs (Lyon et al., 2014). Indeed, a climate which supports innovation, organisational readiness and service provider preparedness for change, has been identified as important to the adoption of service innovations (Durlak \& DuPre, 2008; Glisson, 2007). Communities and organisations therein, often have deeply entrenched policies, processes and 
practices, as well as attitudes and relationships that need to be understood and addressed for effective implementation to occur (Turner, Nicholson \& Sanders, 2011). It is important to note that existing organisational cultures and climates are not necessarily negative (i.e. lack of understanding, inadequate commitment). Indeed, the experiences outlined here, illustrate that resistance to innovation which emerged in the context of Youngballymun, was rooted in priorities, perceptions and preferences regarding "best practices". Commitment and buy-in for innovation was generated when the fit between change efforts and stakeholders' values was addressed.

Our findings provide insight into the types of implementation strategies which may be useful in addressing the issue of appropriateness, as well as helping to extend knowledge of how such implementation strategies should be used in the early stages of implementation. For example, evaluation of need and data gathering is often recommended as a strategy for successful implementation (Kershner et al., 2014). An assessment of readiness, coupled with the identification of barriers and facilitators which may influence a planned intervention, may be particularly important in the early stages of implementation; this may help service providers and funders to identify EBPs with better fit for the context in which implementation is to occur. However, using such strategies in a top-down fashion undermine community engagement with exploration and installation processes. However, fostering a climate which is facilitative of innovation is important to supporting and enabling implementation; thus, a sensitive approach to understanding community needs, which recognises and values stakeholder perspectives on innovation, is vital (Hurlburt et al., 2014; Shapiro et al., 2012). Thus, complementary bottom-up planning strategies which proactively involve key persons at the forefront of service provision and which generate commitment to innovation, can enrich implementation efforts (Aarons, Ehrhart, Farahnak \& Sklar, 2014).

Overcoming the challenge posed by stakeholder resistance to innovation and a lack of perceived fit may be supported by providing a platform for local consensus discussions (Powell et al., 2015). Powell and colleagues describe this particular implementation strategy as involving discussions between local decision makers, practitioners and other stakeholders that address whether an intervention is appropriate and in line with stakeholder priorities. Our findings demonstrate that collaborative planning and negotiation were vital to the successful outcome of the planning process. The development of team structures that included local voices in the exploration and installation process was important in ensuring that the proposed programme of intervention was in line with the needs of the community and the desired goals and interests of core stakeholders. Thus, teams which bring together stakeholders in the implementation process may be a useful platform for such discussions; however, it is important that team members/contributors feel that the process is participatory and that their contributions are valued (Hurlburt et al., 2014).

A responsive approach to implementation planning, which was characterised by flexibility and openness to change, was an important mechanism in the successful progression of exploration and installation. Innovation development frequently involves trial and error, experimentation and revision; thus, programme planners and/or innovators should be allowed sufficient time to build a strategic framework for implementation of new programmes and practices. The process of implementation takes time, and rarely proceeds in a linear straightforward manner (Akin et al., 2017; Barnes, Matka \& Sullivan, 2003). In the 
case study outlined here, the allocation of sufficient time to the exploration and installation phase (e.g. allowing for appropriate adjustments/changes) was important in navigating community/service provider concerns regarding innovation/change, securing buy-in and engagement for the strategy and, ultimately, augmenting strategic capacity for implementation.

\subsection{Lessons learned}

Stakeholder buy-in for innovation is an important consideration in building a foundation for innovation and in creating an environment conducive to the successful implementation of EBPs; however, this clearly requires careful preparation and planning. The case study findings some useful key lessons for the planning of area-based, child-and youth-focused EBPs elsewhere. These are outlined below:

1. At the outset of the planning process, it is important to establish a shared vision which incorporates and respects the priorities and preferences of multiple voices from the local community. This vision should be shared and agreed with a broad range of key stakeholders/service providers early in the planning process and any reservations or potential barriers to implementation identified and resolved.

2. It is necessary to develop an in-depth understanding of the context in which innovation is to occur, particularly stakeholders' priorities and preferences in relation to evidence-based practice and service innovation. This can help planners determine which EBPs may best fit with local conditions, whilst also allowing them to address stakeholder concerns and build more positive attitudes toward practice change.

3. It is crucial that planning efforts for innovation are underpinned by the active involvement of, and collaboration with, community stakeholders from the earliest stages of the planning process. This can help to avoid conflict and resistance to change and secure buy-in for innovation and implementation.

4. A respect for existing work practices and values is also a necessary prerequisite for effective innovation and implementation. Community involvement in the planning process can allow innovators to harness community assets including local knowledge, expertise and skills which can, in turn, be leveraged to enable and ensure successful adoption and implementation of EBPs.

5. Inclusive team structures can facilitate positive communication and feedback processes between key stakeholders involved in the planning process. This can help planners to develop an in-depth understanding of the context in which implementation is to occur and, in turn, facilitate the identification of EBPs which are acceptable to local stakeholders and which fit with community resources and values. Enabling the active participation of stakeholders in the planning process can also help to create a sense of local ownership over innovation and, in turn, generate readiness for change.

6. Lastly, the process of service design is often complex and protracted. Sufficient time should be allowed for exploration and installation and a flexible approach adopted to planning and programme development. Implementation involves a non-linear process and revision and change within that process is not always a setback, but rather an opportunity to strengthen and support innovation development. Such investment in the service planning process can help to facilitate the development of a practicable programme of innovation and, 
in particular, help to embed change initiatives within the community landscape, promote community involvement and buy-in for implementation.

\section{Conclusion}

The importance of evidence-based programmes and practices within child and youth services is now widely accepted by practitioners, policy-makers and politicians alike. Nevertheless, significant barriers exist to the uptake and establishment of EBPs (Szapocznik, Muir, Duff, Schwartz \& Brown, 2015). The findings of the case study reported here, illustrate how stakeholder perceptions and values are a key factor in the process of adopting and installing new programmes and practices within child and youth services. These stakeholder perceptions and attitudes may vary depending on work role, position and/or background and experience; however, EBPs are never implemented in a vacuum and it is important that programme developers and planners recognise such beliefs and preferences as an important aspect of the context in which innovation is to occur. The appropriate management of stakeholder priorities and values, alongside early and meaningful involvement of key stakeholders in planning processes may help to diffuse and/or prevent resistance to change and innovation. The examination of early exploration and installation processes is important in order to improve the efficiency with which intervention strategies can be embedded in usual care services. Moreover, despite recent growth in the field of implementation science, more 'real world' research is needed to facilitate the identification and selection of appropriate implementation strategies which support effective implementation (Akin et al., 2017; Powell et al., 2017). This research, therefore, helps to address an important gap in knowledge by elucidating the importance of the complex interplay between planning processes and stakeholder experiences, values and attitudes.

Some study limitations must be noted. Stakeholder insights into the design and development of the initiative were obtained retrospectively. Interviewees involved in this research may not have recalled accurately and/or overlooked aspects of the processes and activities involved in exploration and installation. The individual characteristics of participants was not collected (e.g. age, experience) and absence of this data may limit the extent to which the findings can be generalised to other circumstances and settings.

Nonetheless, a broad range of stakeholders and large sample of participants were involved in the data collection process, whilst interview/group discussion data was triangulated against findings from the comprehensive document analysis. There remain significant barriers to ensuring that vulnerable children and young people receive high-quality prevention and early intervention services (Horwitz et al., 2010). It is imperative, in the context of increasing commitment to public investment in evidence-based child and youth services, that research is conducted to provide decision makers and services providers with practical information on how complex intervention strategies can be embedded within usual care settings for children and young people. 


\section{Acknowledgements}

This research was funded by Youngballymun with financial support from The Atlantic Philanthropies and the Department of Children and Youth Affairs. We would like to thank all participants who took part in this research, as well as Youngballymun staff for their support of the research. The views expressed herein are those of the authors and not necessarily those of Youngballymun. We also gratefully acknowledge the help and expertise of Professor Elliot Stern during the completion of this research. 


\section{References}

Aarons, G. A., \& Sommerfeld, D. H. (2012). Leadership, innovation climate, and attitudes toward evidence-based practice during a statewide implementation. Journal of the American Academy of Child \& Adolescent Psychiatry, 51, 423-431

Aarons, G. A., Ehrhart, M. G., Farahnak, L. R., \& Sklar, M. (2014). Aligning leadership across systems and organizations to develop a strategic climate for evidence-based practice implementation. Annual Review of Public Health, 35.

Akin, B. A., Strolin-Goltzman, J., \& Collins-Camargo, C. (2017). Successes and challenges in developing trauma-informed child welfare systems: A real-world case study of exploration and initial implementation. Children and Youth Services Review, 82, 4252.

Allen, G. (2011). Early intervention: the next steps, an independent report to Her Majesty's government by Graham Allen MP. The Stationery Office.

Anderson, L. M., Shinn, C., Fullilove, M. T., Scrimshaw, S. C., Fielding, J. E., Normand, J., ... \& Task Force on Community Preventive Services. (2003). The effectiveness of early childhood development programs: A systematic review. American Journal of Preventive Medicine, 24, 32-46.

Ballymun Development Group (2006). Hearing the Voice of Ballymun. Dublin: Ballymun Development Group. http://www.youngballymun.org/fileadmin/user_upload/voiceofballymun_report.pdf

Barnes, M., Matka, E., \& Sullivan, H. (2003). Evidence, understanding and complexity: evaluation in non-linear systems. Evaluation, 9(3), 265-284.

Berkel, C., Mauricio, A. M., Schoenfelder, E., \& Sandler, I. N. (2011). Putting the pieces together: An integrated model of program implementation. Prevention Science, 12, 23-33.

Berlin, L. J., Brooks-Gunn, J., \& Aber, J. L. (2001). Promoting early childhood development through comprehensive community initiatives. Children's Services: Social Policy, Research, and Practice, 4(1), 1-24.

Black, M. M., Walker, S. P., Fernald, L. C., Andersen, C. T., DiGirolamo, A. M., Lu, C., ... \& Devercelli, A. E. (2017). Early childhood development coming of age: science through the life course. The Lancet, 389(10064), 77-90.

Bledsoe, K. L., \& Graham, J. A. (2005). The use of multiple evaluation approaches in program evaluation. American Journal of Evaluation, 26, 302-319.

Boyle, M. (2005). Sartre's circular dialectic and the empires of abstract space: A history of space and place in Ballymun, Dublin. Annals of the Association of the American Geographers, 95, 181-201.

Braun, V., \& Clarke, V. (2006). Using thematic analysis in psychology. Qualitative research in psychology, 3(2), 77-101.

Britto, P. R., Lyes, S., \& Proulx, K. (2016). with the Early Childhood Development Interventions Review Group, for the Lancet Early Childhood Development Series Steering Committee. Nurturing care: promoting early childhood development. Lancet, 31390-3Cabassa, L. J., \& Baumann, A. A. (2013). A two-way street: bridging 
implementation science and cultural adaptations of mental health treatments. Implementation Science, 8(1), 90.

Burns, B. J., Schoenwald, S. K., Burchard, J. D., Faw, L., \& Santos, A. B. (2000). Comprehensive community-based interventions for youth with severe emotional disorders: Multisystemic therapy and the wraparound process. Journal of Child and Family Studies, 9, 283-314.

Cabassa, L. J., \& Baumann, A. A. (2013). A two-way street: Bridging implementation science and cultural adaptations of mental health treatments. Implementation Science, 8, 90.Damschroder, L. J., Aron, D. C., Keith, R. E., Kirsh, S. R., Alexander, J. A., \& Lowery, J. C. (2009). Fostering implementation of health services research findings into practice: a consolidated framework for advancing implementation science. Implementation Science, 4, 50-65.

Cerezo, M. A., Dasi, C., \& Ruiz, J. C. (2013). Supporting parenting of infants: Evaluating outcomes for parents and children in a community-based program. Evaluation and Program Planning, 37, 12-20.

Department of Children and Youth Affairs [DCYA] (2008). Forum on Prevention and Early Intervention for Children and Youth. Dublin: Stationary office.

http://childrensdatabase.ie/documents/publications/Forum report p04.pdf

Durlak, J. A., \& DuPre, E. P. (2008). Implementation matters: A review of research on the influence of implementation on program outcomes and the factors affecting implementation. American journal of community psychology, 41(3-4), 327-350.

Epstein, A. S. (2007). The Intentional Teacher. Exchange.

http://citeseerx.ist.psu.edu/viewdoc/download?doi=10.1.1.476.9053\&rep=rep1\&type= pdf

Fixsen, D.L., Blase, K., Metz, A., \& Van Dyke, M. (2013). Statewide implementation of evidence-based programs. Exceptional Children, 79, 213-230.

Fixsen, D. L., Naoom, S. F., Blase, K. A., \& Friedman, R. M. (2005). Implementation Research: A Synthesis of the Literature. FL: University of South Florida, Louis de la Parte Florida Mental Health Institute, National Implementation Research Network.

Glisson, C. (2007). Assessing and changing organizational culture and climate for effective services. Research on social work practice, 17(6), 736-747.

Government of Ireland (2007). Ballymun Regeneration. Dublin: Stationary Office

Greenhalgh T., Robert G., McFarlane F., Bate P. \& Kyriakidon O. (2004) Diffusion of innovations in service organisations: Systematic review and recommendations. The Milbank Quarterly, 82, 581-629

Hasson, H. (2010). Systematic evaluation of implementation fidelity of complex interventions in health and social care. Implementation Science, 5(1), 67.

Hayes, N. \& Bradley, S. (2006). Ballymun Needs Analysis: Summary Report. Dublin, Young Ballymun.

https://arrow.dit.ie/cgi/viewcontent.cgi?referer=https://www.google.com/\&httpsredir= $1 \&$ article $=1040 \&$ context $=$ cserrep

Heckman, J. J. (2011). The Economics of Inequality: The Value of Early Childhood Education. American Educator, 35, 31. 
Hohmann, M., Weikart, D. P., \& Epstein, A. S. (1995). Educating Young Children. Michigan, High/Scope Educational Research Foundation.

Horwitz, S.M., Chamberlain, P., Landsverk, J. \& Mullican, C. (2010). Improving the mental health of children in child welfare through the implementation of evidence-based parenting interventions. Administration and Policy in Mental Health and Mental Health Services Research, 37, 27-39.

Hurlburt, M., Aarons, G. A., Fettes, D., Willging, C., Gunderson, L., \& Chaffin, M. J. (2014). Interagency collaborative team model for capacity building to scale-up evidencebased practice. Children and Youth Services Review, 39, 160-168.

Kershner, S., Flynn, S., Prince, M., Potter, S. C., Craft, L., \& Alton, F. (2014). Using data to improve fidelity when implementing evidence-based programs. Journal of Adolescent Health, 54(3), S29-S36.

Kintrea, K., \& Muir, J. (2009). Integrating Ballymun? Flawed progress in Ireland's largest estate regeneration scheme. Town Planning Review, 80, 83-108.

Lafferty, C. K., \& Mahoney, C. A. (2003). A framework for evaluating comprehensive community initiatives. Health Promotion Practice, 4, 31-44.

Lyon, A. R., Ludwig, K., Romano, E., Koltracht, J., Vander Stoep, A., \& McCauley, E. (2014). Using modular psychotherapy in school mental health: Provider perspectives on intervention-setting fit. Journal of Clinical Child \& Adolescent Psychology, 43, 890-901

McKeown, K. \& Haase, T. (2006). The mental health of children and the factors which influence it: A study of families in Ballymun. Report for Ballymun Development Group for Children and Young People. http://www.lenus.ie/hse/handle/10147/285266

Metz, A. (2013). Implementation science: Defining the new frontier. In T. Halle, A. Metz \& I. Martinez-Beck (Eds). Applying Implementation Science in Early Childhood Programs and Systems. (pp.1-4). Baltimore: Paul Brooks.

Metz, A., Bartley, L., Ball, H., Wilson, D., Naoom, S., \& Redmond, P. (2015). Active implementation frameworks for successful service delivery: Catawba county child wellbeing project. Research on Social Work Practice, 25, 415-422.

Metzler, M., Merrick, M. T., Klevens, J., Ports, K. A. \& Ford, D. C. (2017). Adverse childhood experiences and life opportunities: Shifting the narrative. Children and Youth Services Review, 72, 141-149.

Moore, G., Audrey, S., Barker, M., Bond, L., Bonell, C., Cooper, C., ... \& Wight, D. (2013). Process evaluation in complex public health intervention studies: The need for guidance. Journal of Epidemiological Community Health, 0, 1-2

Moore, G. F., Audrey, S., Barker, M., Bond, L., Bonell, C., Hardeman, W., ... \& Baird, J. (2015). Process evaluation of complex interventions: Medical Research Council guidance. British Medical Journal, 350, h1258

Naoom, S. F., Blase, K., Fixsen, D. L., Van Dyke, M., \& Bailey, F. W. (2010). Implementing evidence-based programs in the real world: Lessons learned from model program developers and purveyors. Chapel Hill, NC: National Implementation Research Network, FPG Child Development Institute, UNC.

Nilsen, P. (2015). Making sense of implementation theories, models and frameworks. Implementation Science, 10, 53. 
Novins, D.K., Green, A.E., Legha, R.K. \& Aarons, G.A. (2013). Dissemination and implementation of evidence-based practices for child and adolescent mental health: a systematic review. Journal of the American Academy of Child and Adolescent Psychiatry, 52, 1009-1025.

Odom, S. L., Cox, A. W., Brock, M. E., \& National Professional Development Center On Asd. (2013). Implementation science, professional development, and autism spectrum disorders. Exceptional Children, 79, 233-251.

Panzano, P. C., \& Roth, D. (2006). The decision to adopt evidence-based and other innovative mental health practices: Risky business?. Psychiatric Services, 57, 11531161.

Powell, B. J., Waltz, T. J., Chinman, M. J., Damschroder, L. J., Smith, J. L., Matthieu, M. M., ... \& Kirchner, J. E. (2015). A refined compilation of implementation strategies: results from the Expert Recommendations for Implementing Change (ERIC) project. Implementation Science, 10, 21.

Powell, B. J., Beidas, R. S., Lewis, C. C., Aarons, G. A., McMillen, J. C., Proctor, E. K., \& Mandell, D. S. (2017). Methods to improve the selection and tailoring of implementation strategies. The Journal of Behavioural Health Services \& Research, 44, 177-194.

Proctor, E. K., Powell, B. J., \& McMillen, J. C. (2013). Implementation strategies: recommendations for specifying and reporting. Implementation Science, 8, 139.

Proctor, E., Silmere, H., Raghavan, R., Hovmand, P., Aarons, G., Bunger, A., ... \& Hensley, M. (2011). Outcomes for implementation research: conceptual distinctions, measurement challenges, and research agenda. Administration and Policy in Mental Health and Mental Health Services Research, 38, 65-76.

Reding, M. E., Chorpita, B. F., Lau, A. S., \& Innes-Gomberg, D. (2014). Providers' attitudes toward evidence-based practices: is it just about providers, or do practices matter, too?. Administration and Policy in Mental Health and Mental Health Services Research, 41, 767-776.

Repetti, R.L., Taylor, S.E. \& Seeman, T.E. (2002) Risky families. Psychological Bulletin, 128, 330-266.

Rogers, E. M. (2010). Diffusion of Innovations ( $4^{\text {th }}$ Ed). New York: Simon and Schuster. Ryan, G. (2004). Get it right the first time: An education strategy for Ballymun. Ballymun: Ballymun Partnership.

Saunders, R. P., Evans, M. H., \& Joshi, P. (2005). Developing a process-evaluation plan for assessing health promotion program implementation: A how-to guide. Health Promotion Practice, 6, 134-147.

Self-Brown, S., Whitaker, D., Berliner, L., \& Kolko, D. (2012). Disseminating child maltreatment interventions: Research on implementing evidence-based programs. Child Maltreatment, 17, 5 - 10.

Serbin, L.A. \& Karp, J. (2004). The intergenerational transfer of psychosocial risk: Mediators of vulnerability and resilience. Annual Review of Psychology, 55, 333-363.

Shapiro, C.J., Prinz, R.J. \& Sanders, M.R. (2012). Facilitators and barriers to implementation of an evidence-based parenting intervention to prevent child maltreatment: The Triple P positive parenting program. Child Maltreatment, 17, 86-95. 
Somerville-Woodward, R. (2002). Ballymun, A History: Volumes 1 \& 2C.1600-1997. Ballymun: Ballymun Regeneration Ltd.

Sridharana, S., Gob, S., Zinzowc, H., Grayd, A. \& Gutierrez Barrette, M. (2007). Analysis of strategic plans to assess planning for sustainability of comprehensive community initiatives. Evaluation and Program Planning, 30, 105-113.

Szapocznik, J., Muir, J. A., Duff, J. H., Schwartz, S. J., \& Brown, C. H. (2015). Brief strategic family therapy: Implementing evidence-based models in community settings. Psychotherapy research, 25, 121-133.

Tierney, R. J., \& Shanahan, T. (1991). Research on reading-writing relationships: A synthesis and suggested directions. Handbook of Reading Research, 2, 246-280.

Tornatzky, L. G., \& Klein, K. J. (1982). Innovation characteristics and innovation adoptionimplementation: A meta-analysis of findings. IEEE Transactions on Engineering Management, 29, 28-43.

Turner, K. M., Nicholson, J. M., \& Sanders, M. R. (2011). The role of practitioner selfefficacy, training, program and workplace factors on the implementation of an evidence-based parenting intervention in primary care. The Journal of Primary Prevention, 32(2), 95-112.

Webster-Stratton, C., \& Reid, M. J. (2003). The Incredible Years Parents, Teachers and Children Training Series: A multifaceted Treatment Approach for Young Children with Conduct Problems. Washington: Guilford Press. 
Table 1: Youngballymun services, aims and activities*

Ready, Steady, $\begin{aligned} & \text { Aims to improve the wellbeing of very young children in Ballymun from pre-birth to } \\ & \text { throw }\end{aligned}$
- Implementing an enhanced baby development clinic (the Parent-Child Psychological
Support Programme) for all 0-18 month olds and their parents to promote wellbeing in
the parenting context and to strengthen adaptive systems in children
- Supporting mothers' (and their partners') adaptation to pregnancy and supporting the
developing relationship between the mother, partner and the unborn child though the
enhancement of existing services in the community.
- Building the infant mental health capacity and skills of practitioners, families,
programmes and systems to foster secure attachment, infant and toddler health and
development.

\begin{tabular}{|c|c|}
\hline $\begin{array}{l}\text { 3,4,5 Learning } \\
\text { Years }\end{array}$ & $\begin{array}{l}\text { Aims to improve the quality of ECCE service provision to improve holistic } \\
\text { developmental and learning outcomes for children by: } \\
\text { - Providing tailored capacity building activities and mentoring support for practitioners } \\
\text { to support the implementation of Síolta - The National Quality Framework for Early } \\
\text { Childhood Education } \\
\text { - Building the capacity of Early Childhood Care and Education (ECCE) settings to } \\
\text { implement HighScope through the provision of the 'Implementing HighScope } \\
\text { Approach' (IHA) training and work-based, opportunistic, readily available and } \\
\text { reflective coaching support to practitioners to support the translation of HighScope } \\
\text { learning into practice. }\end{array}$ \\
\hline Incredible Years & $\begin{array}{l}\text { Aims to support a whole-school approach to the implementation of Incredible Years } \\
\text { Parent, Child \& Teacher Programmes to improve children's social and emotional } \\
\text { learning by: } \\
\text { - Building the capacity of school communities to implement the Incredible Years } \\
\text { classroom curriculum and teacher classroom management strategies } \\
\text { - Providing ongoing implementation support (e.g. consultation, mentoring, peer support) } \\
\text { to schools \& teachers } \\
\text { - Supporting a whole-school approach to implementation (e.g. integrating delivery of } \\
\text { parent programme across the school, community and family spheres) }\end{array}$ \\
\hline Write-Minded & $\begin{array}{l}\text { Aims to support schools, families and community-based initiatives to improve literacy } \\
\text { outcomes for children \& young people in Ballymun by: } \\
\text { - Providing tailored capacity building, teacher training \& pedagogical support to } \\
\text { integrate proven language and literacy methodologies into teaching across the } \\
\text { curriculum } \\
\text { - Providing whole-school planning support to embed literacy learning across the } \\
\text { curriculum (via balanced literacy framework) } \\
\text { - Enhancing the capacity of parents and community services to foster children's language } \\
\text { \& literacy development }\end{array}$ \\
\hline Jigsaw & $\begin{array}{l}\text { Aims to build capacity in existing systems of health, community and voluntary supports } \\
\text { and services for young people to actively promote and address youth mental health } \\
\text { wellbeing } \\
\text { - Supporting accessible youth mental health services in the community } \\
\text { - Building capacity of local service community to implement a community wraparound } \\
\text { service (WAF/YSP) } \\
\text { - Crisis response systems improvement }\end{array}$ \\
\hline
\end{tabular}

* As is often the case with these types of complex prevention and early intervention programmes, the implementation of Youngballymun has been characterised by continued evolution and development. Since the completion of this research programme, there have been further changes to the Youngballymun service provision model and programme features. For information see www.youngballymun.org. 


\begin{tabular}{|c|c|c|}
\hline Method & Key Sources/Participants & Primary Purposes \\
\hline $\begin{array}{l}\text { Document } \\
\text { analysis }\end{array}$ & $\begin{array}{l}\text { - } \text { Meeting minutes \& reports } \\
\text { - Youngballymun logic model } \\
\text { - Youngballymun implementation plan } \\
\text { - Other Youngballymun documentation } \\
\text { (information sheets, website etc ) } \\
\text { - Youngballymun policy papers } \\
\text { - Official policy documents and demographic } \\
\text { data }\end{array}$ & $\begin{array}{l}\text { - Examining the initial conceptualisation of } \\
\text { Youngballymun and subsequent } \\
\text { development; } \\
\text { - Identifying challenges to the design and } \\
\text { development of Youngballymun } \\
\text { - Gaining insight into the design of } \\
\text { individual services } \\
\text { - Identifying challenges to the development } \\
\text { and implementation of the services }\end{array}$ \\
\hline
\end{tabular}

\begin{tabular}{lll}
\hline One-to-one & - & Ballymun Development Group members \\
in-depth & - & Youngballymun executive \& service staff \\
interviews & - & Service design and implementation team \\
& & members \\
& - Board members \\
- & Partner organisation staff \\
& - Government/funders representatives
\end{tabular}

- Exploring the perceived main aims, objectives and outcomes of Youngballymun

- Understanding the design, development and implementation of Youngballymun

- Understanding barriers/facilitators for the achievement of outcomes

- Understanding the impact of contextual factors on the Youngballymun initiative

\begin{tabular}{llll}
\hline Group & - & Youngballymun executive staff & - As above \\
discussions & - Youngballymun service staff & \\
& - Implementation team members \\
& - Service staff \\
& - Local service providers
\end{tabular}




\section{Box 1: Outline of the planning process framework}

1. Capture the 'community voice' (i.e. consultations with local residents and community leaders)

2. Capturing 'children's voices' (i.e. consultations with children and young people)

3. Auditing existing services within the community

4. Reviewing existing evidence of what works (i.e. identifying evidence-based services)

5. Conducting a local needs analysis

6. Reviewing evidence of existing need

7. Reviewing the national policy context

8. Engaging with key stakeholders and decision makers 


\section{Box 2: Selection of comments relating to 'Resistance to Innovation'}

"It is very hard to remember it [Youngballymun] as such a fledgling little Joe Soap organisation [...] People were really angry that you have been huddling around for a couple of years and we are only being brought into it now at this phase and plans written. So there was quite a bit of resistance early on". [I6, BDG member]

"They [a local organisation] felt they had no input whatsoever into the shape of the programme and the implementation of any of the work." [I3, BDG member / Youngballymun board member]

"And I think there can be a sense of Youngballymun being critical or judgemental of what was here before and you know... and then a resistance, you know, there is nothing wrong with what we do, what we do is perfectly good..." [G1, Local service provider - health sector]

"I think collectively between us we had something liked 288 years experience of being in Ballymun [...] it was like there was always that thing of coming in and telling us" [I10, Local service provider education sector]

"I didn't think that the voices of experienced [service providers] were heard or valued and I particularly think that the [service] was excluded a lot.” [I14, Local service provider - education sector]

"I don't think they really respected the knowledge that the [service providers] have out [...]. I think that was a mistake." [I6, Local service provider - local government]

"We would have had difficulties, there were decisions made that we were not consulted about" [G5, Local service provider - Education sector]

"There is a sense of that, historical sense of we were here when there was no money and we were here making do and you're at this advantage because [Youngballymun] got all this money and there's a perception that it's this big cash machine that's making decisions ..." [G5, Local service provider Education sector]

"The people there weren't really as engaged, like they were there because they were representing their organisation, but whether they saw themselves in any way as part owner if you like, of the thing [Youngballymun], you would have doubts about that." [15, Youngballymun board member]

"You would say Ballymun had a very developed and you might say cynical long history of disappointment and frustration and various efforts to save the place." [115; Funder]

"I am not sure what you class as a consultation but I don't feel that there was a consultation in the way that I would view a consultation [...] It was made very clear from the start that they were going through a very scientific process and they had to be very true to the model and this was completely unique, $a$ new way of thinking and that really what everyone else was doing up until now wasn't up to that much in comparison to what was going to be delivered through this new model" [I16; Local service provider - Community and voluntary sector] 